\title{
TC-325 application leading to transient obstruction of a post-sphincterotomy biliary orifice
}

TC-325 (Hemospray, Cook Medical Inc., Bloomington, Indiana, USA), a novel endoscopic hemostatic powder has been approved in many countries for nonvariceal gastrointestinal bleeding. It consists of a proprietary inorganic powder, which, when put in contact with moisture, becomes coherent and adhesive, creating a mechanical barrier and effecting hemostasis. Preliminary results in benign and malignant upper and lower gastrointestinal bleeding are promising [1-4]. Optimal indications and technical limitations are still being characterized [5].

We recently treated a patient presenting with hematemesis 12 hours after choledocholithiasis removal, in whom endoscopy confirmed oozing from the sphincterotomy site. Hemostasis occurred immediately following application of $5 \mathrm{~g}$ (1/4 canister) Hemospray; however, resulting arrest of bile flow and caking of the orifice with the powder were noted. Biliary patency was quickly restored with vigorous water irrigation and prodding open of the papillotomy orifice with a sphincterotome tip; prolonged hemostasis was achieved with epinephrine injection. Subsequent follow-up at 4 months after the procedure did not reveal any clinical stigmata of gastrointestinal bleeding ( $\bullet$ Fig. 1).
TC-325 appears highly effective in achieving initial hemostasis [1 -5], yet technical difficulties related to the first-generation delivery system have included blockage of the 10-Fr catheter or the accessory channel of the endoscope if there is premature contact with moisture. Initial flushing of the accessory channel with air using a syringe before introduction of the catheter is thus recommended. Additional limitations include kinking of the delivery system's soft catheter sheath when the endoscope is looped or positioned over a duodenoscope elevator. Recently, 7-Fr and 10-Fr catheters have been marketed as part of a secondgeneration delivery system. TC-325 powder application so far appears quite safe, with no reported bowel obstruction or systemic embolization [1-5]. Here we have reported transient biliary obstruction following successful use of Hemospray in post-sphincterotomy hemorrhage. Caution should therefore be taken when applying hemostatic powders near small orifices adjacent to the bowel lumen.

\section{Endoscopy_UCTN_Code_CPL_1AK_2AI}

Competing interests: Alan Barkun received research funding and is a consultant for Cook Inc., Sarvee Moosavi and Yen-I Chen do not have any conflict of interest to report.

\section{S. Moosavi ${ }^{1}$, Y. I. Chen ${ }^{1}$, A. N. Barkun ${ }^{1,2}$}

${ }^{1}$ Divisions of Gastroenterology, McGill University Health Centre, McGill University, Montréal, Québec, Canada

2 Epidemiology Biostatistics and Occupational Health, McGill University Health Centre, McGill University, Montréal, Québec, Canada

\section{References}

1 Sung JJ, Luo D, Wu JC et al. Early clinical experience of the safety and effectiveness of Hemospray in achieving hemostasis in patients with acute peptic ulcer bleeding. Endoscopy 2011; 43: 291-295

2 Chen YI, Barkun AN, Soulellis C et al. Use of the endoscopically applied hemostatic powder TC-325 in cancer-related upper GI hemorrhage: preliminary experience (with video). Gastrointest Eendosc 2012; 75 : $1278-1281$

3 Soulellis C, Carpenter S, Chen YI et al. Lower gastrointestinal hemorrhage controlled with endoscopically applied TC-325: (with videos). Gastrointest Endosc Jan 2, 2013 [Epub ahead of print]

4 Morris A, Smith L, Stanley A et al. 284 hemospray for non-variceal upper gastrointestinal bleeding: results of the seal dataset (survey to evaluate the application of hemopsray in the luminal tract). Gastrointest Endosc 2012; 75: AB133-AB134

5 Moosavi S, Barkun A. Case-series: utility of Hemospray ${ }^{\mathrm{TM}}$ in management of benign upper and lower GI bleed of various etiologies: preliminary experience. Can J Gastroenterol 2012; 26: A081

Bibliography

Dol http://dx.doi.org/

10.1055/s-0032-1326370

Endoscopy 2013; 45: E130

(c) Georg Thieme Verlag KG

Stuttgart · New York

ISSN 0013-726X

\section{Corresponding author}

\section{Dr A. Barkun}

Division of Gastroenterology

McGill University Health Centre

Montreal General Hospital Site

1650 Cedar Avenue, Room D7-346

Montréal

Canada H3G 1A4

Fax: +514-834-8531

alan.barkun@muhc.mcgill.ca 